\title{
Effect Of Inorganic Fertilizers And Control On The Growth Of The Varieties Of Maize
}

\author{
${ }^{1}$ R. E. Ogunsakin, ${ }^{2}$ K. A Oguntuase ${ }^{3}$ A. O Adesina \\ ${ }^{I}$ Department of Mathematical Sciences, Ekiti State University, Ado Ekiti, Nigeria. \\ ${ }^{2}$ Department ofMathematical and Physical Sciences, Afe Babalola University, Ado Ekiti \\ ${ }^{3}$ Department of Mathematics and Statistics, The Polytechnic Ibadan, Oyo State
}

\begin{abstract}
This paper was statistical experimental design to analyze and compare the effect of various inorganic manures on the growth of varieties of maize (Zea mays) in agricultural sector and their significances. Randomised complete block design was employed in analysis of data obtained from secondary source. From the employed analysis of variance test to examine the significance of the effect of inorganic fertilizers on different varieties of maize, the following facts were deduced: the null hypothesis of factor A, which is inorganic fertilizer for the height of the plant, the number of leaves per plant were accepted at 0.05 level of significance. Similarly, the null hypothesis for factor $B$ which is varieties of maize for the number of leaves and height per plant were accepted at 0.05 level of significance. It shows that there is s significant difference in growth of maize when various inorganic fertilizers were applied. Finally, any of the inorganic manures must always be use in order to increase the growth and yield of maize.
\end{abstract}

Keywords: Randomized complete block design, Inorganic, Fertilizer.

\section{Introduction}

Maize (zea mays) is among the most important cerael crops after rice and wheat. It is grown as edible fruit which can be eaten raw or cooked or made into powder. Maize (Zea mays) can also be used for maize flour, semovita, masa, corn starch, corn syrup and kitty litter.

In Nigeria, maize is grind for chicken to eat. It is edible by man, goat, cows and a lot more. Soils are the provision of foods and fibre for the sustenance of mankind. Earlier, inorganic manure serves as a major plant nutrient. The long effect of inorganic fertilizers on soil management practices might not be encouraged as it encourages disintegration of the soil aggregate reduce infiltration, encourage erosion and leaching. Moreso, the cost of buying the fertilizers is getting out of the reach of the local farmers. The need therefore arise to search for better way to manage our soil properly by using materials which can be obtained at a cheaper rate. It also depends on the types of fertilizer that want to be applied to the soil and the nature of the soil. In a situation whereby the soil is not fertile, Nitrogen, Phosphorus can be used, NPK can also be used to increase the nitrogen, phosphorus and potassium in the soil and other elements.

This experiment therefore was to compare the effect of different inorganic manure on the growth of varietiesof maize and know their significance. It will help and enable the society as a whole to have more knowledge on the effect of various inorganic manure on the growth of varieties of maize production in agricultural sectors.

Like every other experiment carried out in many fields, statistical experiment is an investigation whih involves the manipulation and control of one or more independent variables and observing their effect on one or more dependent variables.

To be able to know the effect of inorganic manure on the growth of varieties of maize (Zea mays), there must be introduction of statistical experimental design. Design of experiment must be considered for accurate result of statistical experiment. Design of experiment is one in which the analyst controls of level of the treatment. In this aspect, to get the accurate result in conducting an experiment for the effect of inorganic manure on the growth of varities of maize production. Statistical experimental design has to be used. Field studies on the integrated nutrient management in maize.

Wahua (1999) defines analysis of variance as an arithmetical procedure of partitioning the total variability in a set of observations among the possible sources of variability in the analysis of variance. The estimation of what fraction of the observed variability is attributable of each of the known source is made. Some assumptions are also made in such estimations, like the error terms are assumed to be randomly independently and normally distributed with mean zero and common variance. The two designs (CRD and RCBD) are under ANOVA. The CRD (Complete Randomised Design) as the name implies, the treatments are completely randomised into the experimental area. For the complete randomised design (CRD) to be appropriate, the source of variation should be two namely, variation due to different variations used and variations within each variation 
used. While randomised complete block design (RCBD) is used when it is possible to run all the treatment combinations in each group such group is called block.

According to Oparah (2005), the randomised complete block design (RCBD) is used more frequently than any other design and it gives satisfactory precision.

(Steel and Torrie 1980) opined in field experiment each block usually consists of a compact nearly squared group of plot.

According to Sharma et al (1987) opined that significant increase in plant height and number of leaves per plant with each successive increase in the level of fertilizer. Addition of 12tonnes of farm yard manure per $\mathrm{ha}^{-1}$ along with fertilizers levels up to $60 \mathrm{kgN}, 30 \mathrm{kgP}_{2} \mathrm{O}_{5}$ and $30 \mathrm{~kg} \mathrm{~K}_{2} \mathrm{O}$ per ha ${ }^{-1}$ significantly improved the growth characters.

Agboola (1999) reported that manure constituted the chief source of crop nutrient before 1990s and beyond in maintaining soil fertility in humid tropics.

Cochran and Cox (1957) found metfrom experiment carried out at Rothamsted experimental station between 1927 and 1974 that the error mean square for RCBD was sixty percent of the error for CRD.

According to Montgomery (1976) for statistical approach in designing and analyzing an experiment to be useful, it is necessary that the researcher has a clear understanding of the steps in experimentation. Agawel et al (1995) reported that application of NPK fertilizer improve root and leaf of the maize.

Adeniyi et al (1991) reported that the fertility of the soil can be lost as a result of nutrient uptake by plants, leaching, erosion and lack of efficient management practice. So the low performance of maize in control plot could be due to low organic matter in the soil content which eventually affects the growth and the yield, whereby inorganic fertilizer is recommended to be used so as to increase the soil content for effective growth and yield.

\section{Complete Randomized Block Design with Interraction}

\section{Background to the Analysis}

Complete randomized block design utilizes experimental units that are matched sets, assigning one from each set treatment. The matched sets of experimental units are called blocks. The concept of the complete randomized block design is that the sampling variability of the experimental units in each block will be reduced The word in interaction has a very specific meaning in the context of (CBRD) We say there is interaction if $Y$ depends on factor A differently for different values of factor B, and vice versa. Similarly, there is no interaction if $\mathrm{Y}$ depends on factor $\mathrm{A}$ in the same way for all values of factor B, and vice versa.(Hinkle Mann and Kempthrone 2008).

This analysis is used when there are two or more fixed-effect factors. Usually the aim is to see whether these interaction.

This experiment takes consideration of the different in experiment materials in the course of experimentation. It is a two-way classification model with interaction, designed to control extraneous source of variation. Present here are two qualitative independent variables namely: Block and Treatment. This analysis is used when there are two or more fixed-effect factors. Usually the aim is to see whether these interaction.

\section{Data Arrangement of Complete Randomized Block Design With Interaction}

Factor A

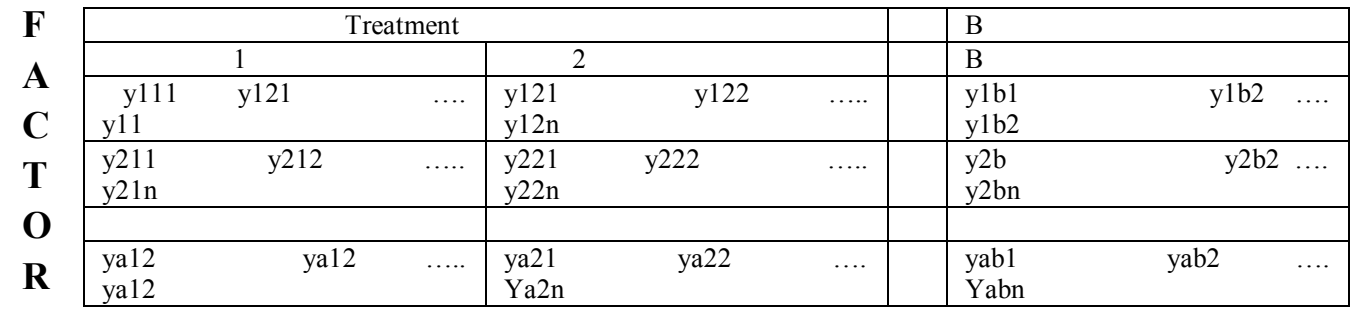

\section{Statistical Model}

$\mathrm{Y}_{\mathrm{ijk}}=\mu+\tau_{\mathrm{i}}+\beta_{\mathrm{j}}+(\tau \beta)_{\mathrm{ij}}+\mathrm{e}_{\mathrm{ijk}}$

For $\mathrm{i}=1,2, . . \mathrm{t}, \mathrm{j}=1,2, \ldots \mathrm{b}, \mathrm{k}=1,2, . . \mathrm{n}$., $\mu=$ represent overall mean, $\tau_{\mathrm{i}}=$ represent the treatment effect of the row. $\beta_{\mathrm{j}}=$ represent the effect of the jth column, $(\tau \beta) \mathrm{ij}=$ represent the interaction effect, $\mathrm{e}_{\mathrm{ij \textrm {k }}}=$ represent the error . Where $\mathrm{y}_{\mathrm{ijk}}$ is the kth observation at the ith level of A and jth level of B and is the error term. 
Anova Table for a Complete Randomized Block Design With Interaction

\begin{tabular}{|l|l|l|l|l|}
\hline Source of variation & Degree of freedom & Sum of square & Mean of square & F ratio \\
\hline Treatment & $\mathrm{t}-1$ & $\mathrm{SStr}$ & $\mathrm{SStr} / \mathrm{t}-1$ & $\mathrm{MSTr} / \mathrm{MSE}$ \\
\hline Blocks & $\mathrm{b}-1$ & $\mathrm{SSb}$ & $\mathrm{SSb} / \mathrm{b}-1$ & $\mathrm{MSB} / \mathrm{MSE}$ \\
\hline Interaction & $(\mathrm{t}-1)(\mathrm{b}-1)$ & $\mathrm{SSb} \times \mathrm{t} /(\mathrm{t}-1)(\mathrm{t} \times \mathrm{b}-1)$ & $\mathrm{MSt} \times \mathrm{t} / \mathrm{MSE}$ \\
\hline Error & By difference & $\mathrm{SSE}$ & & \\
\hline Total & nbt-1 & $\mathrm{SST}$ & & \\
\hline
\end{tabular}

III. Methodology

COMPUTATION ANALYSIS OF DATA

The table below show the data collected for this project.

Table 4.0.1: Number of leaves per plant.

\begin{tabular}{|l|l|l|l|l|}
\hline Varieties Of Maize & & $\mathbf{F}_{\mathbf{1}}(\mathbf{N P K})$ & $\mathbf{F}_{\mathbf{2}}$ (UREA) & $\mathbf{F}_{\mathbf{3}}$ (CONTROL) \\
\cline { 2 - 5 } & Maize 1 & 15.1 & 16.2 & 16.8 \\
\cline { 2 - 5 } & Maize 2 & 11.7 & 12.7 & 11.7 \\
\hline
\end{tabular}

\section{Fertilizer}

Factor A (Inorganic fertilizer)

$\mathrm{F}_{1}-\mathrm{NPK} 1515$

$\mathrm{F}_{2}$ - UREA

$\mathrm{F}_{3}$ - Control

Factor B (Varieties of maize)

Maize 1 - white maize

Maize 2 - yellow maize

In this table above there are three (3) levels of factor A and two (2) levels of factor B.

The number of leaves of maize has influenced by diferrent inorganic fertilizer when the number of leaves per plant kis counted.

\section{Analysis Of Number Of Leaves Per Plant}

Hypothesis for treatment (fertilizer)

\begin{tabular}{|l|l|l|l|l|l|}
\hline Varieties Of Maize & & F1(NPK) & F2(UREA) & F3(CONTROL) & Total Yi \\
\cline { 2 - 6 } & Maize 1 & 15.1 & 16.2 & 16.8 & 48.1 \\
\cline { 2 - 6 } & Maize 2 & 11.7 & 12.7 & 11.7 & 36.1 \\
\hline & Y .j & 26.8 & 28.9 & 28.5 & 84.2 \\
\hline
\end{tabular}

$\mathrm{H}_{\mathrm{O}}$ : the average number of leaves of the maize due to the fertilizers are not significantly different.

i.e. $\quad \mathrm{H}_{\mathrm{O}}: \mathrm{F}_{1}=\mathrm{F}_{2}=\mathrm{F}_{3}=0$

$\mathrm{H}_{\mathrm{O}}: \breve{\mathrm{t}}_{1}=\breve{\mathrm{t}}_{2}=\breve{\mathrm{t}}_{3}=0$

$\mathrm{H}_{1}$ : the average number of leaves of maize in the three (3) inorganic fertilizers are significantly different for at least one fertilizer.

i.e. $\mathrm{H}_{1}$ : at least $\mathrm{F}_{1} \neq 0$

Hypothesis for block (varieties of maize)

$\mathrm{H}_{\mathrm{O}}$ : there is no significant different in the average number of leaves of the two varieties.

i.e. $H_{\mathrm{O}}: \beta_{1}=\beta_{2}=0$

$\mathrm{H}_{1}$ : there is significant different in the average number of leaves of the two varieties.

i.e. $\mathrm{H}_{1}$ : at least one $\beta_{\mathrm{j}} \neq 0$

Where level of significance $(\alpha)=0.05$

\section{Analysis For Height Of Varieties Per Plant}

\begin{tabular}{|l|l|l|l|l|l|}
\hline \multirow{3}{*}{$\begin{array}{l}\text { Varieties Of } \\
\text { Maize }\end{array}$} & & F1(NPK) & F2(UREA) & F3(CONTROL) & TOTAL Y.. \\
\cline { 2 - 6 } & Maize 1 & 171.1 & 163.3 & 178 & 512.4 \\
\cline { 2 - 6 } & Maize 2 & 124.8 & 147.7 & 151.6 & 424.1 \\
\cline { 2 - 6 } & Total Y.j & 295.9 & 311 & 329.6 & 936.5 \\
\hline
\end{tabular}

\section{Hypothesis For Fertilizer}

$\mathrm{H}_{\mathrm{O}}$ : There is no significant different in the average height of maize due to the effect of the three (3) fertilizers under consideration.

i.e. $\quad \mathrm{H}_{\mathrm{O}}: \mathrm{F}_{1}=\mathrm{F}_{3}=0$

$\mathrm{H}_{1}$ : There is significant different in the average height of maize due to the effect of the three (3) fertilizers. 
i.e $\mathrm{H}_{1}$ : at least $\mathrm{F}_{1} \neq 0$

\section{Hypothesis For Block (Varieties of maize)}

$\mathrm{H}_{\mathrm{O}}$ : There is no significant different in the average height of maize in the two (2) varieties of maize considered. i.e. $\beta_{1}=\beta_{2}=0$

$\mathrm{H}_{1}$ : There is significant different in the average height of maize in the two (2) varieties of maize considered.

Using level of significance $(\alpha)=0.05$

\section{Test Statistics: Analysis Of Variance (ANOVA)}

The Model:

$$
\mathrm{Y}_{\mathrm{ij}}=\mu+\check{\iota}_{\mathrm{i}}+\beta_{\mathrm{j}}+\mathrm{e}_{\mathrm{ij}}
$$

\section{Interpretation Of Results}

Based on the results of the various test performed in the proceeding chapters of this project, some readable facts can be deduced. Employing analysis of variance test to examine the significance of manure effect on different varieties of maize (Zea mays)

The null hypothesis for factor A which is inorganic manure was accepted at 0.05 level of significance. i.e. $\mathrm{F}_{\text {cal }}=1.3626<\mathrm{F}_{\mathrm{tab}}=19.0$

This indicates that factor A are not significantly different from one another. i.e. the differnt level of inorganic manure applied did not resulted in the number of leaves of varieties (Maize). Also in the height of plant, the null hypothesis for factor A was accepted at 0.05 level of significance.

i.e. $\mathrm{F}_{\mathrm{cal}}=1.1749<\mathrm{F}_{\mathrm{tab}}=19.0$

Similar the number of leaves per plant, the null hypothesis for factor B.

i.e. $\mathrm{F}_{\mathrm{cal}}=52.747>\mathrm{F}_{\mathrm{tab}}=18.5$ which is varieties of maize was rejected at 0.05 level of significance. This shows that, there is significant different between the two maize.

Furthermore, the heightof varieties per plant, the null hypothesis for factor B was accepted at 0.05level of significance.

i.e. $\mathrm{F}_{\mathrm{cal}}=10.716<\mathrm{F}_{\mathrm{tab}}=18.5$

This indicates that there is no significant difference in the height of maize when the various inorganic fertilizer were applied.

\section{Conclusion}

Inorganic manure is a major contributing factor in the growth and yield of maize (Zea mays). However, it was discovered that inorganic manure contribute mostly to the yield of maize. It could therefore be concluded that any one of inorganic manure should always be used in order to further increase the growth and yield of maize (Zea mays).

\section{Recommendation}

In any research institute, the focus of any research or analysis is knowing which factors contribute to the growth and yield of a particular crop. Obviously, maize is a common and widely used cereal crop across the globe and especially Nigeria.

Therefore, the role of maize in Nigeria economy cannot be overemphasized. Though high percentages of income are in agricultural sector, it is a very domestic consumption.

Inorganic manure in crop growth serve as catalyst to chemical reaction, hence farmers should be oriented, exposed and taught the use and application of fertilizer to their respective crops.

Demonstration farm settlement should be provided so that variety needed more for a certain nutrients can be detected and such variety is planted into the soil that is rich in that nutrient.

\section{References}

[1]. Cochran W.G and Cox G (1957). Experimental Design, Macmillian Co; NY, USA (2nd edition)

[2]. Little T.M and Hills F.J. (1997). Agricultural experimentation. John Wiley and Sons: NY USA.

[3]. Montgomery D.C (1976). Design and Analysis of Experiments. 2nd edition. Wiley and Sons: NY, USA

[4]. Murrary R.S and Larry J.S. (2008). Theory and Problems of Statistics. 4th edition. USA. McGraw Hill.

[5]. Oparah C.K (2005). "On two approaches of balance incomplete block design ". unpublished MSc thesis. University of Nigeria, Nsukka.

[6]. Steel R. and Torrie J (1980). Principles and procedures of statistics: a biometrical approach (2nd edition). USA. McGraw Hill.

[7]. Wahua T.A.T (1999). Applied Statistics for Scientific Students. 2nd edition. Africa Link Books. Owerri, Ibadan, Abuja 